\title{
Article
}

\section{Neochlorogenic Acid Attenuates Hepatic Lipid Accumulation and Inflammation via Regulating miR-34a In Vitro}

\author{
Meng-Hsun Yu ${ }^{1,2,+}$, Tung-Wei Hung ${ }^{3,4,+}$, Chi-Chih Wang ${ }^{4,5} \mathbb{D}$, Sheng-Wen Wu ${ }^{3,4}$, Tzu-Wei Yang ${ }^{4,5}$, \\ Ching-Yu Yang ${ }^{1}$, Tsui-Hwa Tseng ${ }^{6,7, *}$ and Chau-Jong Wang $2,8, *$ \\ 1 Institute of Medicine, Chung Shan Medical University, Taichung 40201, Taiwan; \\ ya780522@gmail.com (M.-H.Y.); apink222@livemail.tw (C.-Y.Y.) \\ 2 Department of Health Industry Technology Management, Chung Shan Medical University, \\ Taichung 40201, Taiwan \\ 3 Department of Medicine, Division of Nephrology, Chung Shan Medical University Hospital, \\ Taichung 40201, Taiwan; a6152000@ms34.hinet.net (T.-W.H.); s41111.tw@yahoo.com.tw (S.-W.W.) \\ 4 School of Medicine, Chung Shan Medical University, Taichung 40201, Taiwan; \\ bananaudwang@gmail.com (C.-C.W.); joviyoung@gmail.com (T.-W.Y.) \\ 5 Division of Gastroenterology and Hepatology, Department of Internal Medicine, Chung Shan Medical \\ University Hospital, Taichung 40201, Taiwan \\ 6 Department of Medical Applied Chemistry, Chung Shan Medical University, Taichung 40201, Taiwan \\ 7 Department of Medical Education, Chung Shan Medical University Hospital, Taichung 40201, Taiwan \\ 8 Department of Medical Research, Chung Shan Medical University Hospital, Taichung 40201, Taiwan \\ * Correspondence: tht@csmu.edu.tw (T.-H.T.); wcj@csmu.edu.tw (C.-J.W.); \\ Tel.: +886-4-247-30022 (ext. 12230) (T.-H.T.); +886-4-247-30022 (ext. 11670) (C.-J.W.) \\ check for \\ updates \\ + These authors contributed equally to this work and share first authorship.
}

Citation: Yu, M.-H.; Hung, T.-W.; Wang, C.-C.; Wu, S.-W.; Yang, T.-W.; Yang, C.-Y.; Tseng, T.-H.; Wang, C.-J Neochlorogenic Acid Attenuates Hepatic Lipid Accumulation and Inflammation via Regulating miR-34a In Vitro. Int. J. Mol. Sci. 2021, 22, 13163. https://doi.org/10.3390/ ijms222313163

Academic Editor:

Natália Cruz-Martins

Received: 24 October 2021

Accepted: 30 November 2021

Published: 6 December 2021

Publisher's Note: MDPI stays neutral with regard to jurisdictional claims in published maps and institutional affiliations.

Copyright: (c) 2021 by the authors. Licensee MDPI, Basel, Switzerland. This article is an open access article distributed under the terms and conditions of the Creative Commons Attribution (CC BY) license (https:// creativecommons.org/licenses/by/ $4.0 /)$.

\begin{abstract}
Neochlorogenic acid (5-Caffeoylquinic acid; 5-CQA), a major phenolic compound isolated from mulberry leaves, possesses anti-oxidative and anti-inflammatory effects. Although it modulates lipid metabolism, the molecular mechanism is unknown. Using an in-vitro model of nonalcoholic fatty liver disease (NAFLD) in which oleic acid (OA) induced lipid accumulation in HepG2 cells, we evaluated the alleviation effect of 5-CQA. We observed that 5-CQA improved OA-induced intracellular lipid accumulation by downregulating sterol regulatory element-binding protein 1 (SREBP1) and fatty acid synthase (FASN) expression, which regulates the fatty acid synthesis, as well as SREBP2 and HMG-CoA reductases (HMG-CoR) expressions, which regulate cholesterol synthesis. Treatment with 5-CQA also increased the expression of fatty acid $\beta$-oxidation enzymes. Remarkably, 5-CQA attenuated OA-induced miR-34a expression. A transfection assay with an miR-34a mimic or miR-34a inhibitor revealed that miR-34a suppressed Moreover, Sirtuin 1 (SIRT1) expression and inactivated $5^{\prime}$ adenosine monophosphate-activated protein kinase (AMPK). Our results suggest that 5-CQA alleviates lipid accumulation by downregulating miR-34a, leading to activation of the SIRT1/AMPK pathway.
\end{abstract}

Keywords: 5-CQA; NAFLD; fatty acid synthesis; cholesterol synthesis; miR-34a

\section{Introduction}

The liver is the main organ controlling cholesterol and fatty acid metabolism. Excessive lipid accumulation in the liver is associated with several diseases, such as diabetes, atherosclerosis, and NAFLD [1]. NAFLD occurrence may precede the development of more severe liver diseases, including cirrhosis and hepatocellular carcinoma [2]. Therefore, appropriate regulation of hepatic lipid metabolism is crucial to prevent dyslipidemia. The expression of FASN and HMG-CoR, the enzymes essential for the regulation of fatty acid and cholesterol synthesis, is to be considered markers of lipogenesis [3]. Conversely, the expression of carnitine palmitoyl transferase-1 (CPT1) and peroxisome proliferator-activated receptor $\alpha(\operatorname{PPAR} \alpha)$ is predominantly associated with fatty acid oxidation. In addition, 
sterol regulatory element-binding proteins (SREBPs) are a family of membrane-bound transcription factors that activate genes encoding enzymes required for cholesterol and unsaturated fatty acid synthesis. SREBP1 activates the transcription of genes required for fatty acid and fatty acid synthesis; SREBP2 modulates the transcription of genes required for cholesterol synthesis [4,5]. It is directly or indirectly modulated by AMPK, an energy-sensing protein complex, to regulate the process of lipid homeostasis [6,7]. Moreover, SIRT1, a nicotinamide adenine dinucleotide-dependent deacetylase, may be required for AMPK activation and the regulation of the transcriptional network of cellular lipid metabolism involved in NAFLD progression [8]. Activation of AMPK in the liver by nutraceutical/pharmaceutical compounds may inhibit fatty acid synthesis and promote fatty acid oxidation $[9,10]$. Therefore, the SIRT1/AMPK pathway is one of the promising targets in NAFLD prevention.

MicroRNAs are small noncoding RNAs that mediate the post-transcriptional regulation of gene expression by binding to the $3^{\prime}$ untranslated regions ( $3^{\prime}$-UTRs) of the target mRNAs. Dysregulation of miRNAs disrupts the gene regulatory network, leading to the development of metabolic syndrome and related diseases [11,12]. Therefore, modulating miRNA expression using natural products has been highlighted as a mechanism for preventing and treating metabolic diseases or cancers [13,14]. miR-34a has multiple roles in the regulation of cell cycle, apoptosis, and differentiation. In addition, increasing the expression of miR-34a has been indicated to lead to NAFLD development $[15,16]$. Thus, miR-34a is implied to be a useful target for alleviating lipid-associated metabolic diseases.

Mulberry leaves (Morus alba L.), the most common component of a silkworm's diet, is an edible food used to treat metabolic disorders, such as diabetes, dyslipidemia, fatty liver diseases, and hypertension, in Asia. Our previous study demonstrated the bioactivity of mulberry leaf extract (MLE) against hepatic lipogenesis and inflammation to alleviate liver injury induced by ethanol [17]. MLE has also been reported to prevent obesityinduced NAFLD by regulating adipocytokines, inflammation, and oxidative stress $[18,19]$. Previous studies have shown that the anti-hepatic steatosis of mulberry leaves involves the regulation of the inflammatory response and autophagy pathway in the liver tissue of HFD-induced obesity mice [20]. Our previous study identified polyphenols in MLE, including rutin, quercetin, chlorogenic acid, and 5-CQA. Among them, 5-CQA was the most abundant polyphenol [17]. Accumulating evidence has demonstrated that 5-CQA exhibits many biological properties, including antibacterial, antioxidative, and anticarcinogenic activities, particularly hypoglycemic and hypolipidemic effects [21-23]. A study recently claimed that 5-CQA modulated glucose and lipid metabolism, in vivo, among both healthy individuals and those with genetic metabolism disorders [24,25].

However, the molecular mechanism of the effects of 5-CQA on lipid metabolism is unknown. In the present study, we established an in-vitro model through OA-induced lipid accumulation in HepG2 cells. Our hypothesis is that 5-CQA alleviates hepatic lipid accumulation by downregulating miR-34a, leading to the activation of the SIRT1/AMPK pathway, which modulates the expression of lipogenesis and lipid $\beta$-oxidation enzymes as well as lipogenesis-associated transcription factors.

\section{Results}

\subsection{Effect of 5-CQA and OA on the Viability of HepG2 Cells}

NAFLD is also known to be caused by hepatic lipid accumulation and is associated with diabetes and metabolic syndrome [26]. In addition, previous studies showed that OA could induce lipid accumulation in hepatocytes [27]. The MTT assay was performed to evaluate the effect of 5-CQA and OA on the viability of HepG2 cells. As shown in Figure $1 \mathrm{~A}, \mathrm{~B}$, treatment with 50-300 $\mu \mathrm{M}$ 5-CQA for $24 \mathrm{~h}$ or $48 \mathrm{~h}$ was not cytotoxic to HepG2 cells. In addition, HepG2 cells exhibited no cytotoxicity upon co-treated with 5-CQA $(40-120 \mu \mathrm{M})$ and $\mathrm{OA}(300 \mu \mathrm{M})$ for $24 \mathrm{~h}$ or $48 \mathrm{~h}$ (Figure 1C,D). In parallel, cell morphology was not affected by the 5-CQA treatments for $24 \mathrm{~h}$ (Figure 1E). Taken together, these results revealed that 5-CQA treatments had no significant effects on the cell viability of HepG2 
cells. Therefore, we want to explore the role of 5-CQA in future experiments of OA-induced lipid accumulation of HepG2 cells. Subsequently, we use OA to stimulate the production of lipid accumulation, and subsequent NAFLD condition model (OA cultured HepG2 cells).

(A)

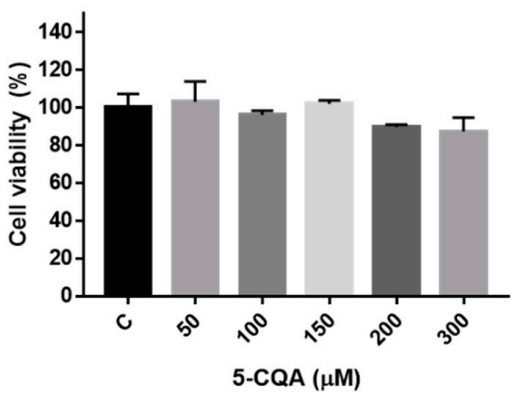

(C)

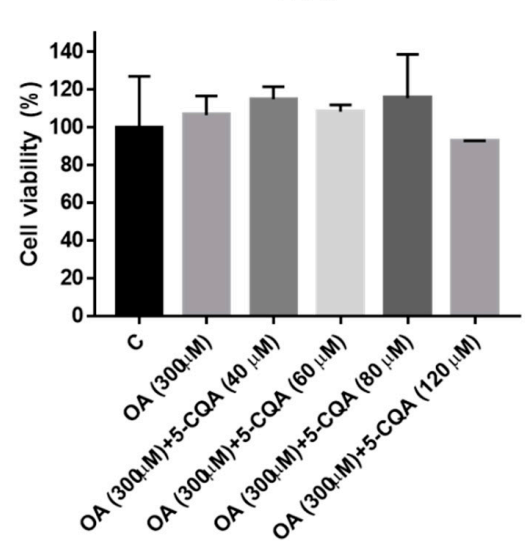

(B)

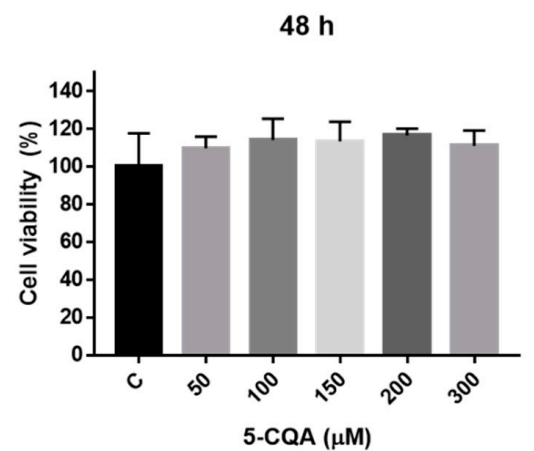

$48 \mathrm{~h}$

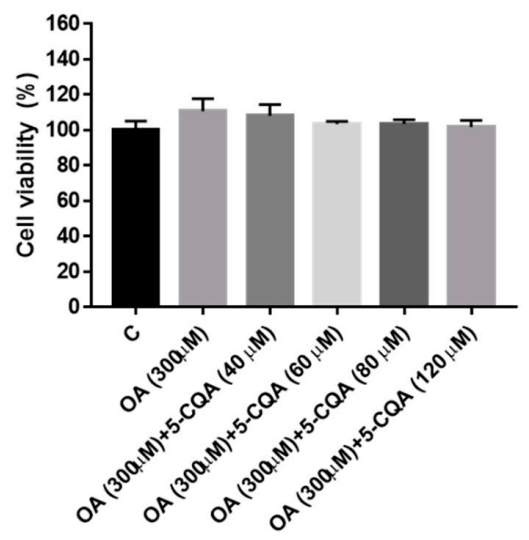

(E)

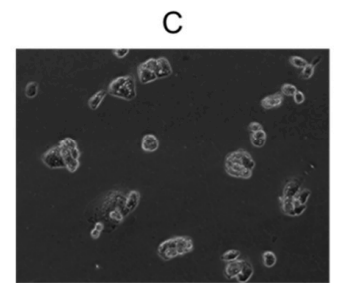

5-CQA: $150 \mu \mathrm{M}$

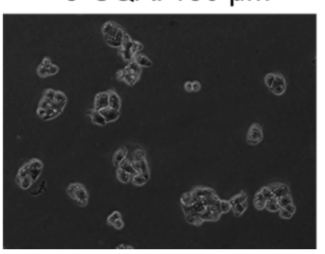

5-CQA: $50 \mu \mathrm{M}$

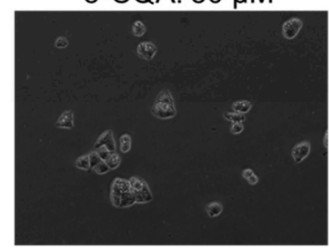

5-CQA: $200 \mu \mathrm{M}$

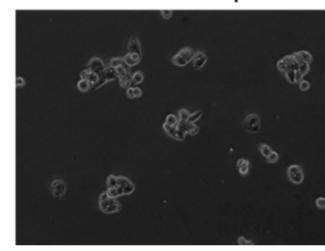

5-CQA: $100 \mu \mathrm{M}$

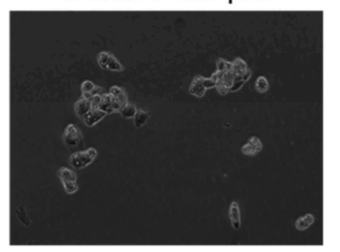

5-CQA: $300 \mu \mathrm{M}$

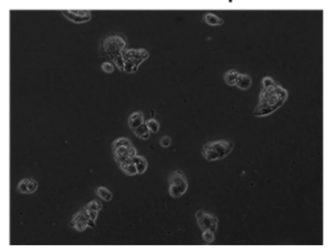

Figure 1. Cytotoxicity of HepG2 cells after treatment with 5-CQA. (A) Cultured HepG2 cells were treated with various concentrations of 5-CQA for $24 \mathrm{~h}$ and analyzed using the MTT assay. (B) Cultured HepG2 cells were treated with various concentrations of 5-CQA for $48 \mathrm{~h}$ and analyzed using the MTT assay. (C) Cultured HepG2 cells were co-treated with various concentrations of 5-CQA with OA $(300 \mu \mathrm{M})$ for $24 \mathrm{~h}$ and analyzed using the MTT assay. (D) Cultured HepG2 cells were co-treated with various concentrations of 5-CQA with OA $(300 \mu \mathrm{M})$ for $48 \mathrm{~h}$ and were then analyzed using the MTT assay. (E) Cells were treated with indicated concentrations of 5-CQA for $24 \mathrm{~h}$ and then the cell morphology was monitored by phase-contrast microscopy. The data are expressed as mean $\pm \mathrm{SD}$ from three samples for each group. 


\subsection{Effect of 5-CQA on OA-Induced Lipid Accumulation}

Using an Oil Red O staining assay, we detected the intracellular lipid content in HepG2 cells after co-treated with 5-CQA and OA for $24 \mathrm{~h}$ to evaluate whether 5-CQA can reduce lipid accumulation. Figure 2A demonstrates the intense red staining in HepG2 cells upon OA administration, whereas co-treatment with 5-CQA decreased the intensity of the color comparatively. Quantitative data demonstrated that 5-CQA significantly reduced OA-induced neutral lipid accumulation in HepG2 cells. Moreover, the Nile red flow cytometry analysis for lipid droplets showed that 5-CQA significantly reduced OA-induced fluorescence (Figure 2B). Taken together, these results revealed that 5-CQA treatments reduced lipid accumulation in a dose-dependent manner.

(A)
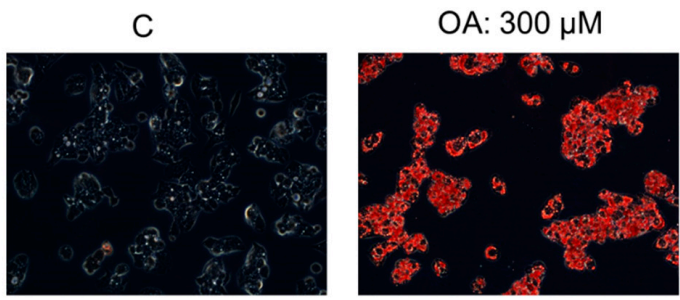

OA: $300 \mu \mathrm{M}$ 5-CQA: $40 \mu \mathrm{M}$

OA: $300 \mu \mathrm{M}$

5-CQA: $80 \mu \mathrm{M}$

OA: $300 \mu \mathrm{M}$

5-CQA: $120 \mu \mathrm{M}$
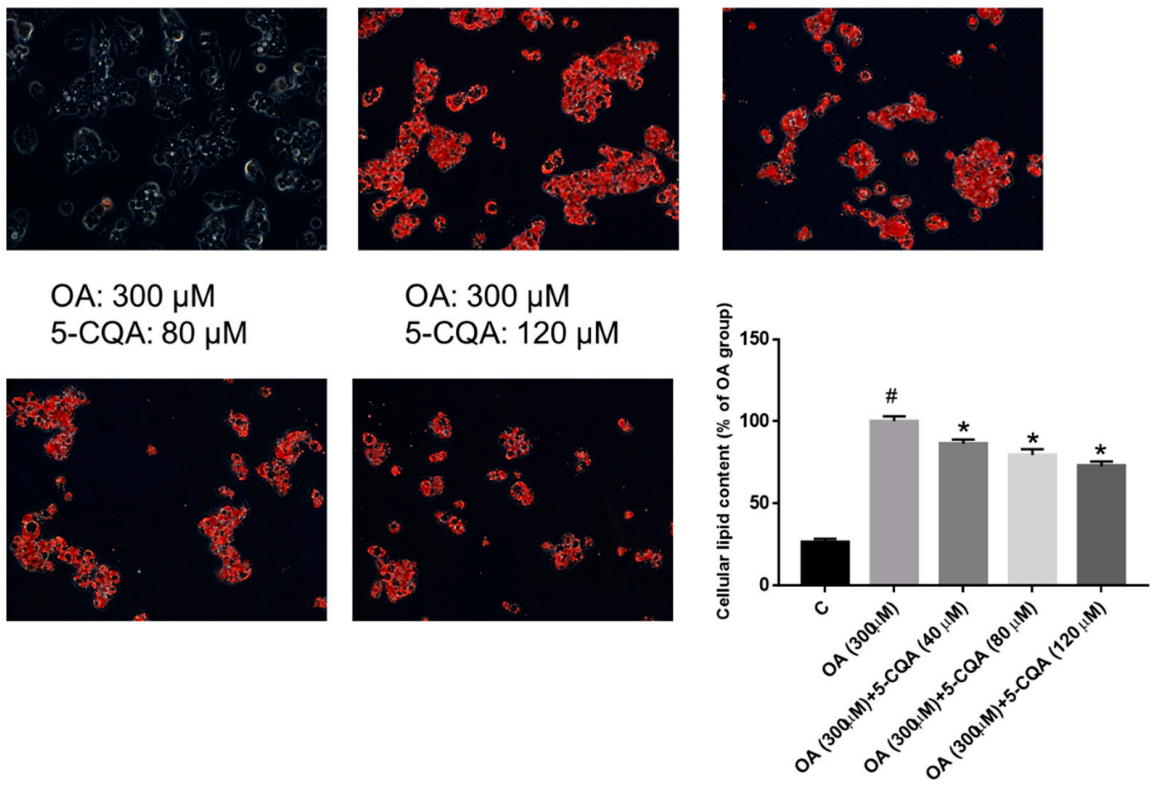

(B)
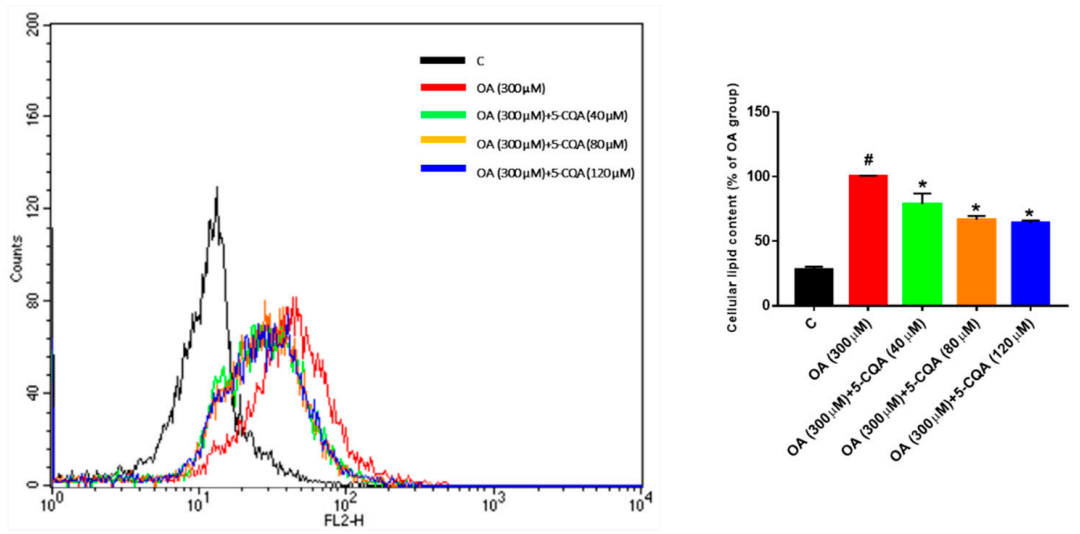

Figure 2. 5-CQA attenuated oleic acid (OA)-induced lipid accumulation in HepG2 cells. (A) Cultured cells demonstrated lipid accumulation induced by OA $(300 \mu \mathrm{M})$ for $24 \mathrm{~h}$. Cells were co-treated with OA and indicated concentrations of 5-CQA $(40,80$, or $120 \mu \mathrm{M})$ for $24 \mathrm{~h}$. Cellular neutral lipid was stained with Oil Red O and the representative photo was taken. Quantitation was determined using colorimetric analysis as described in the text. (B) Lipid accumulation was determined by the Nile red flow cytometry analysis. The cellular lipid content (a minimum of 10,000 cells per sample) was measured using BD biosciences FACscan with CellQuestTM Pro software. The data are expressed as mean \pm SD from three independent samples for each group. \# $p<0.05$, in relation to the control group. ${ }^{*} p<0.05$, in relation to the OA-induced group. 


\subsection{Effect of 5-CQA on OA-Induced Fatty Acid and Cholesterol Synthesis}

To identify the mechanisms involved in the reduction of hepatic lipid accumulation by 5-CQA, we investigated the expression of lipogenic proteins including SREBP, FASN, and HMG-CoR. In Figure 3, 5-CQA significantly reduced the OA-induced expression of SREBP1 and FASN, which are involved in fatty acid synthesis. Furthermore, Figure 4 demonstrates that 5-CQA significantly suppressed OA-induced expression of SREBP2 and HMG-CoR, which are involved in cholesterol synthesis. Taken together, these findings demonstrated that lipogenesis-related proteins were dose-dependently reduced in response to 5-CQA treatments.

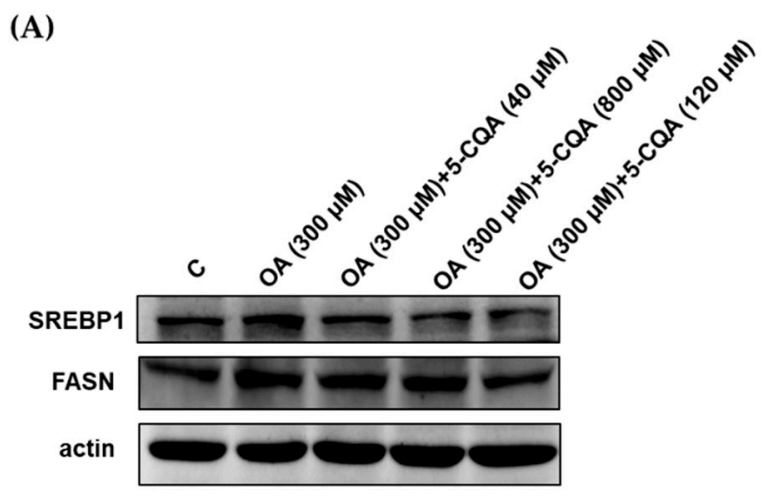

(B)

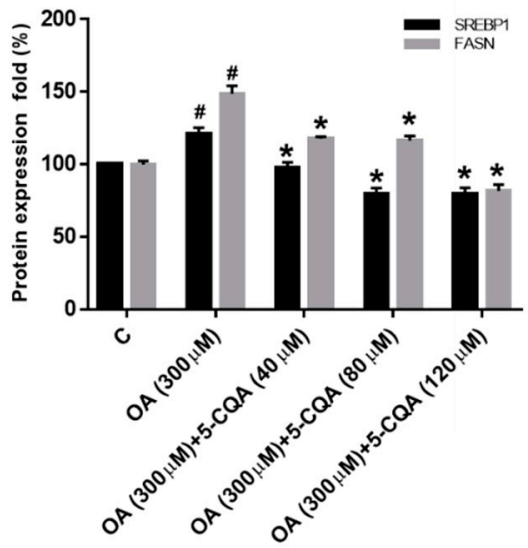

Figure 3. 5-CQA decreased the expression of enzymes involved in fatty acid synthesis. (A) The cells were treated with OA with or without 5-CQA $(40,80$, or $120 \mu \mathrm{M})$ for $24 \mathrm{~h}$. Protein expression was detected by Western blot analysis against SREBP1 and FASN antibodies, with anti-actin as the internal control. (B) The data are presented as mean \pm SD from three samples for each group. $\# p<0.05$, in relation to control group. ${ }^{*} p<0.05$, in relation to OA-induced group.

(A)

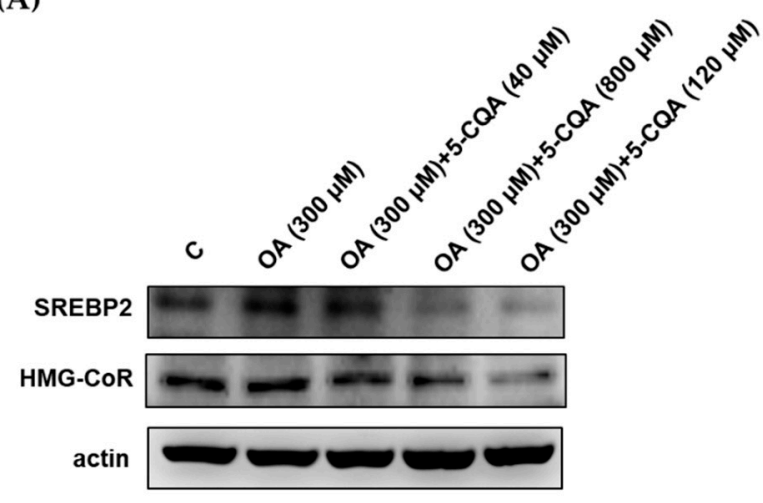

(B)

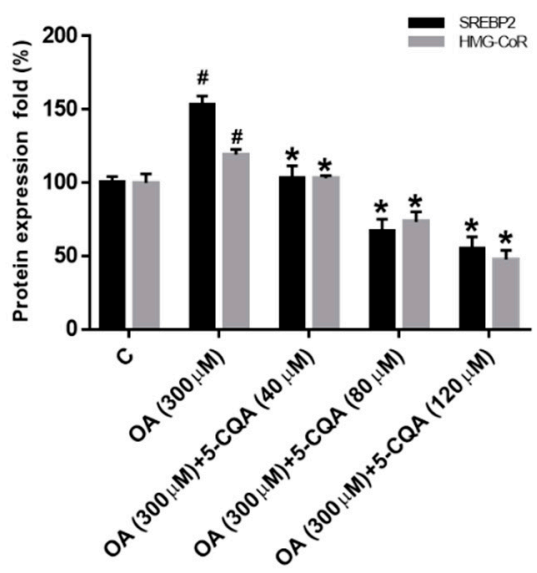

Figure 4. 5-CQA decreased the expression of enzymes involved in cholesterol synthesis. (A) Cultured cells were treated with OA with or without 5-CQA $(40,80$, or $120 \mu \mathrm{M})$ for $24 \mathrm{~h}$. Protein expression was detected using Western blot analysis against SREBP2 and HMG-CoR antibodies, with anti-actin as the internal control. (B) The data are represented as mean $\pm \mathrm{SD}$ from three samples for each group. \# $p<0.05$, in relation to the control group. ${ }^{*} p<0.05$, in relation to the OA-induced group. 


\subsection{Effect of 5-CQA on OA-Induced Defect of Fatty Acid Oxidation and Inflammation}

Several studies have suggested that augmented fatty acid oxidation may protect against steatosis [28,29]. Therefore, we evaluated the effect of 5-CQA on the expression of PPAR $\alpha$ and CPT1, which are involved in fatty acid oxidation. As shown in Figure 5, OA treatment reduced the expression of PPAR $\alpha$ and CPT1 significantly compared with the control, whereas coadministration with 5-CQA reversed the effects. TNF $\alpha$ has been reported as a mediator of inflammation and plays a critical role in the pathogenesis of NAFLD. We determined the effect of OA on the expression of TNF $\alpha$ and NFKB, which are involved in the inflammatory signal pathway. OA significantly promoted the expression of NFKB and TNF $\alpha$ (Figure 6). Furthermore, co-treated of OA with 5-CQA reduced the OA-induced expression of NFKB and TNF $\alpha$ (Figure 6).

(A)

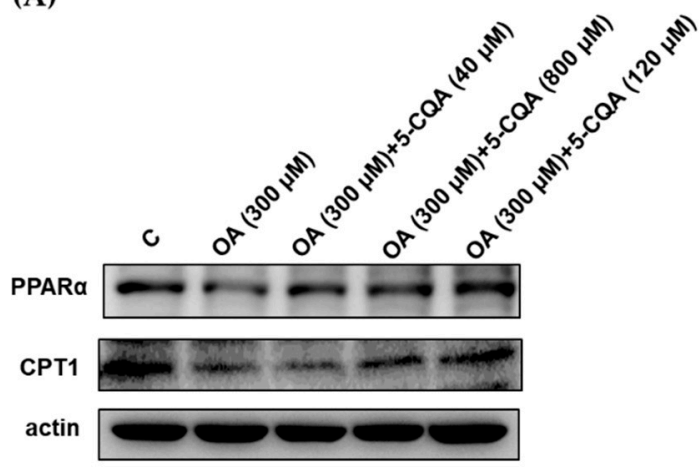

(B)

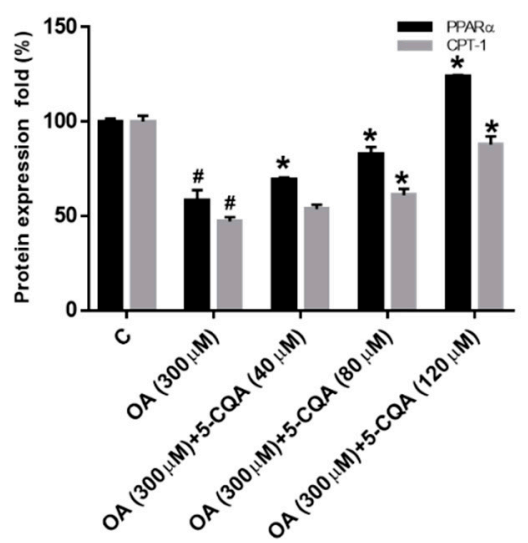

Figure 5. 5-CQA increased the expression of enzymes involved in fatty acid oxidation. (A) Cultured cells were treated with OA with or without 5-CQA $(40,80$, or $120 \mu \mathrm{M})$ for $24 \mathrm{~h}$. Protein expression was detected using Western blot analysis against PPAR $\alpha$ and CPT1 antibody, with anti-actin as the internal control. (B) The data are represented as mean \pm SD from three samples for each group. \# $p<0.05$, in relation to control group. ${ }^{*} p<0.05$, in relation to OA-induced group.

(A)

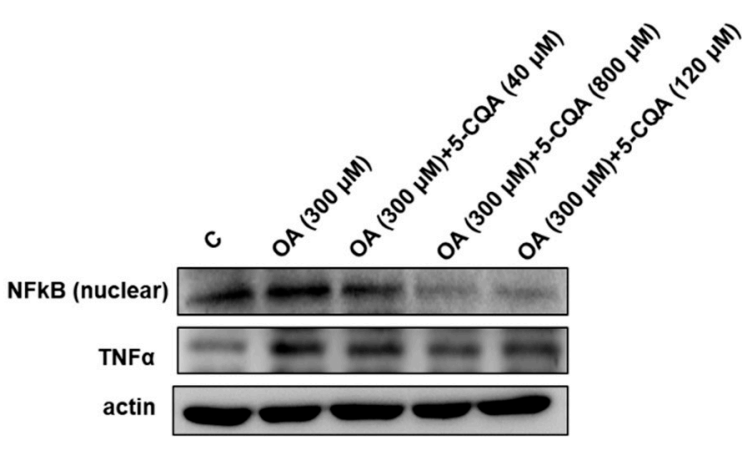

(B)

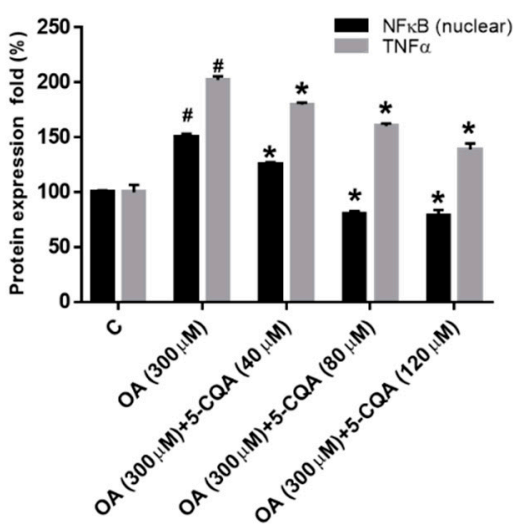

Figure 6. 5-CQA decreased the expression of inflammatory mediators. (A) Cultured cells were treated with OA with or without 5-CQA $(40,80$, or $120 \mu \mathrm{M})$ for $24 \mathrm{~h}$. Protein expression was detected using Western blot analysis against NFkB (nuclear) and TNF $\alpha$ antibody, with anti-actin as the internal control. (B) The data are represented as mean $\pm \mathrm{SD}$ from three samples for each group. $\# p<0.05$, in relation to control group. ${ }^{*} p<0.05$, in relation to OA-induced group. 


\subsection{Effect of 5-CQA on the miR-34a/SIRT1/AMPK Pathway}

miR-34a has been demonstrated to be a critical regulator of lipid metabolism [16]. In the current study, Figure 7A demonstrates that OA induced miR-34a expression, which was reduced upon co-treatment with 5-CQA. The increase in miR-34a has been reported to be responsible for decreasing the expression of SIRT1, resulting in steatosis [30]. To confirm the contribution of SIRT1 and AMPK to miR-34a regulation, the expression of SIRT1 and phospho-AMPK was determined. As shown in Figure 7B, the expression of SIRT1 and phospho-AMPK was downregulated after transfection with an miR-34a mimic and upregulated after transfection with an miR-34a inhibitor (Figure 7B). The Oil Red $\mathrm{O}$ staining assay demonstrated that transfection with the miR-34a inhibitor decreased OA-induced lipid accumulation in HepG2 cells (Figure 7C).

(A)

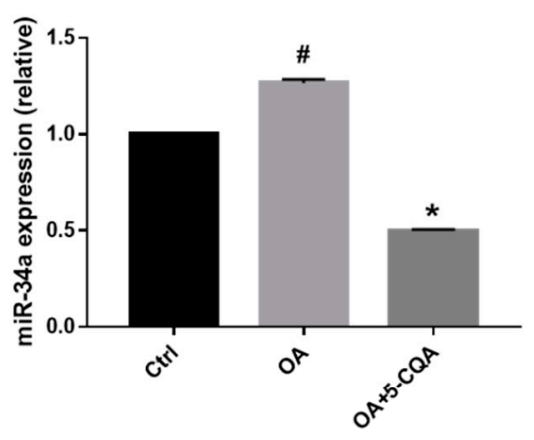

(B)
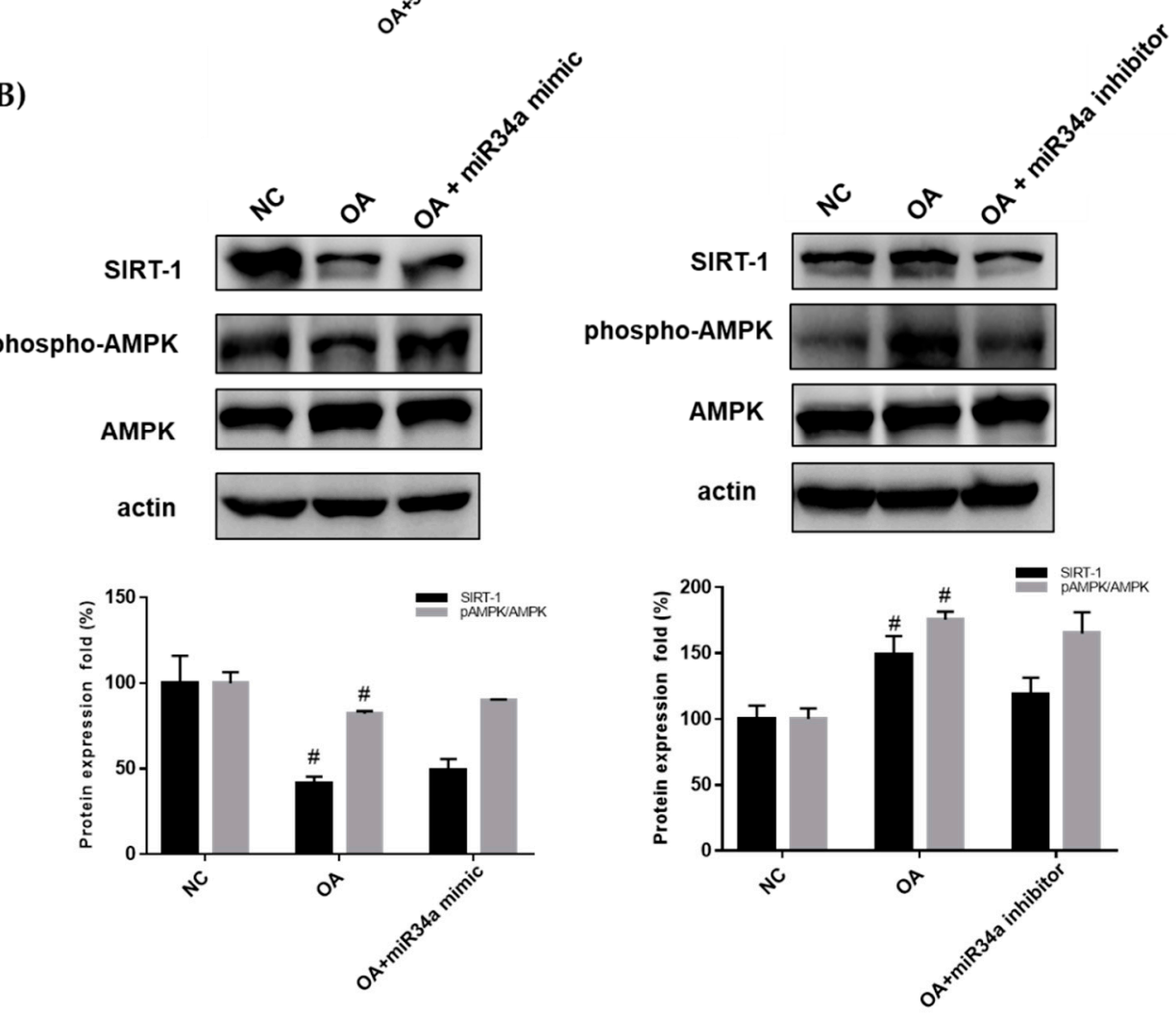

phospho-AMPK

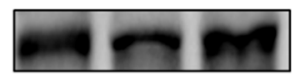

phospho-AMPK

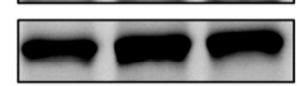

AMPK

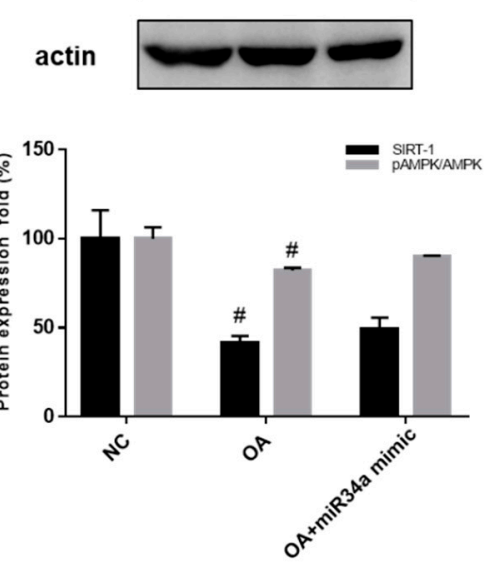

Figure 7. Cont. 
(C)
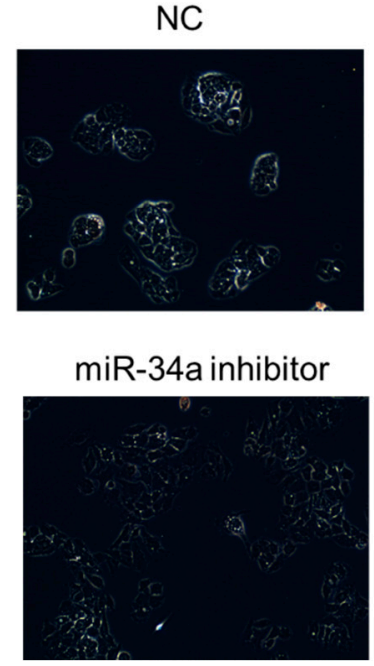

$\mathrm{OA}$

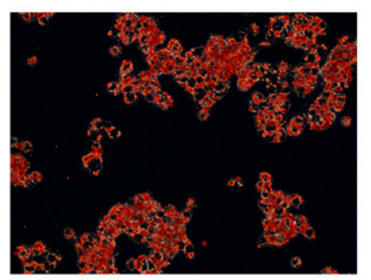

$\mathrm{OA}+\mathrm{miR}-34 \mathrm{a}$ inhibitor

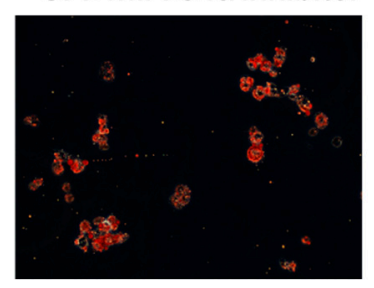

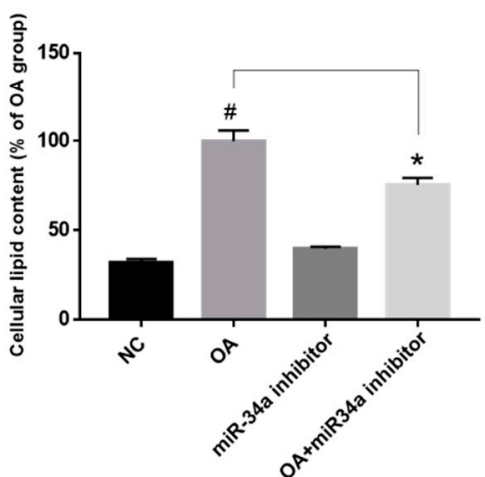

Figure 7. The effect of 5-CQA on miR-34a expression and the effect of miR-34a on lipid accumulation. (A) The cells were co-treated with OA and 5-CQA for $24 \mathrm{~h}$. The level of miR-34a was analyzed as described in the text. Treatment with 5-CQA decreased the expression of miR-34a. The results are presented as mean $\pm \mathrm{SD}$ from three independent experiments for each group. \# $p<0.05$, in relation to the control group. ${ }^{*} p<0.05$, in relation to the OA-induced group. Ctrl, control; OA, oleic acid. (B) After transfection with miR-34a mimic or inhibitor, the total cell lysate (protein) was analyzed using immunoblotting against SIRT1, phosphor-AMPK, AMPK, and actin antibody. The data are presented as mean $\pm \mathrm{SD}$. \# $p<0.05$, in relation to the negative control group. (C) After miR-34a inhibitor transfection, cells were treated with or without OA for $24 \mathrm{~h}$. The intracellular lipid was stained with Oil Red $\mathrm{O}$ and the representative photo was taken. The quantification was determined using colorimetric assay as described in the text. The data are presented as the mean \pm SD of three samples of each group. $\# p<0.05$, in relation to the negative control group. ${ }^{*} p<0.05$, in relation to the OA-treated group.

\section{Discussion}

Dysregulation of lipid metabolism leading to excessive lipid accumulation in the liver is a major risk factor for development of life-threatening diseases such as NAFLD. NAFLD is a prevalent chronic disease worldwide and is associated with hypertriglyceridemia, insulin resistance, and metabolic syndrome [26]. The progression of NAFLD may lead to the development of nonalcoholic steatohepatitis, liver fibrosis and cirrhosis, or hepatoma, which have a poor prognosis [2]. In addition to lifestyle adjustment, the major treatment strategy for NAFLD is the development of medicinal or preventive agents to improve lipid homeostasis. In recent years, we found key molecular drivers on treatments were targeted NAFLD, including regulating carbohydrate-responsive element-binding protein (ChREBP) to inhibit obesity and insulin-resistant ob/ob mice to reverse hepatic steatosis. Furthermore, stearoyl-CoA desaturase-1 (SCD1) is one of the key enzymes of lipogenesis, hence the inhibition of SCD1 reduced steatohepatitis [31]. Previous study demonstrated pioglitazone (a thiazolidinedione) is a peroxisome proliferator-activated receptor $\gamma$ (PPAR $\gamma$ ) agonist that improves steatosis, inflammation, and ballooning in patients with NAFLD [32]. F0AT1 (SLC6A19) inhibitor ameliorates the lipotoxicity and dyslipidemia to induce endogenous fibroblast growth factor 21 (FGF21) to treat fatty liver associated diseases [33].

Dietary polyphenols have recently attracted attention for their biological and pharmacological effects. Various studies have reported that natural polyphenols can regulate gene expression through epigenetic machinery to prevent metabolic abnormalities [34]. Luteolin prevents cholesterol synthesis through the reduction of HMGCR expression by suppressing SREBP-2 transcription and post-translational modification in hepatic cells [6]. Naringin treatment can significantly decrease hepatic total cholesterol concentration and hepatic triglyceride concentration. It also can activate AMPK, and lead to changes in the expression of low-density lipoprotein receptor (LDLR), SREBPs and proprotein convertase subtilisin/kexin type 9 (PCSK9), thereby inhibiting obesity in C57BL/6J mice [35]. Epige- 
netic mechanisms for modulating chromatin accessibility include DNA methylation and histone acetylation, methylation, and phosphorylation. In addition, miRNAs regulate gene expression at the level of translation by degrading mRNA or inhibiting its translation [36]. These mechanisms represent novel targets for polyphenols in the prevention and treatment of diseases. In the present study, 5-CQA, a polyphenol, suppressed OA-upregulated miR34a expression, implicating that 5-CQA modulated lipid homeostasis through epigenetic machinery. Our previous animal study demonstrated that MLE could prevent NAFLD, and that 5-CQA was the highest phenolic component in MLE [17]. Therefore, 5-CQA was suggested to be a major functional component of MLE. Additionally, the previous study indicated other plants were also found to be rich in 5-CQA, such as caraway, coltsfoot, white mulberry, tarragon, lovage, and green coffee beans, and it was found that 5-CQA improved the proliferation of cancer cells or the exacerbation of the cardiovascular disease $[37,38]$. Furthermore, $5-\mathrm{CQA}$ induces the activity of antioxidant, and scavenges reactive oxygen species (ROS), which suppresses the expression of inflammation and the inhibition of PPAR $\gamma$, and then prevents and improves liver steatosis [39]. Thus, 5-CQA can be promising candidates to prevent NAFLD by antioxidant and anti-inflammatory properties. miRNAs are a class of endogenous noncoding RNAs that can directly target numerous mRNAs, including factors implicated in signal transduction pathways and transcription factors, by modulating gene expression. miRNAs have been implicated to exert crucial functions in various biological processes, including growth, development, metabolic activity, and diseases [40]. Growing evidence has revealed that miRNAs participate in lipid metabolism [41]. Patients with NAFLD have been reported to exhibit an increased expression of miR-34a, which was parallel to the increase in fatty acid accumulation [42]. Conversely, another report demonstrated that reduced miR-34a expression could inhibit lipid accumulation and alleviate hepatocellular steatosis in mouse liver [15]. Consistent with our results, 5-CQA decreased OA-induced lipid accumulation in HepG2 cells, which was associated with the downregulation of miR-34a. In addition, most miRNAs are produced from primary transcripts that are converted into precursor miRNAs (pre-miRNAs) by the RNase III Drosha. Pre-miRNAs are subsequently exported to the cytoplasm, where the RNase III Dicer within the RISC complex cleaves the hairpin of miRNA, resulting in the formation of mature microRNA. Our investigation found that only 5-CQA, an isomer of chlorogenic acid, significantly decreased OA-induced lipid accumulation in HepG2 cells. miRNA expression is a complex process involving multiple enzymes. The stereospecificity of 5-CQA might play a critical role in the expression of miR-34a, which requires further clarification.

The present study was performed using an in-vitro NAFLD model in which OA induced fat deposition and cytokine production in HepG2 cells. We demonstrated that 5-CQA reduced OA-induced intracellular lipid accumulation by suppressing the expression of SREBPs, FASN, and HMG-CoR, which are associated with lipogenesis; 5-CQA also reversed OA-downregulated PPAR $\alpha$ and CPT1, which are essential for modulating transportation, uptake, and $\beta$-oxidation of fatty acids. In addition, 5-CQA suppressed OA-induced expression of TNF- $\alpha$ and NFKB. Thus, our study results demonstrated that 5-CQA can improve lipid homeostasis.

AMPK is a vital regulator of cellular energy homeostasis. AMPK activation inhibits the expression of acetyl CoA carboxylase and FAS by downregulating SREBPs, thus reducing the synthesis of fatty acids, cholesterols, and triglycerides and promoting fatty acid uptake and $\beta$-oxidation [10]. Furthermore, SIRT1, a nicotinamide adenine dinucleotide-dependent deacetylase, can induce mitochondrial biogenesis and suppress the gene transcription involved in adipogenesis [43]. SIRT1 has been observed to be inhibited by miR-34a, and it regulates the activity of AMPK [44]. Polyphenols have been reported to possess therapeutic potential for dyslipidemia by targeting SIRT1/AMPK signaling, which plays an essential role in the regulation of hepatocyte lipid metabolism [45]. Chlorogenic acid has been indicated to activate AMPK, resulting in suppressing hepatic glucose production and fatty acid synthesis [46]. CQA is one of the pivotal polyphenols found in natural food, coffee, 
and certain plant species, such as mulberry leaves $[47,48]$. Multiple isomeric forms of CQA, such as 3-CQA, 4-CQA, and 5-CQA, display antioxidant activity [49]. Our study results imply that 5-CQA, an isomer of chlorogenic acid, alleviated NAFLD by modulating the miR-34a/SIRT1/AMPK pathway. In conclusion, our results demonstrated that 5-CQA can downregulate miR-34a, leading to the activation of the SIRT1/AMPK pathway, resulting in the alleviation of hepatic lipid acumination (Figure 8).

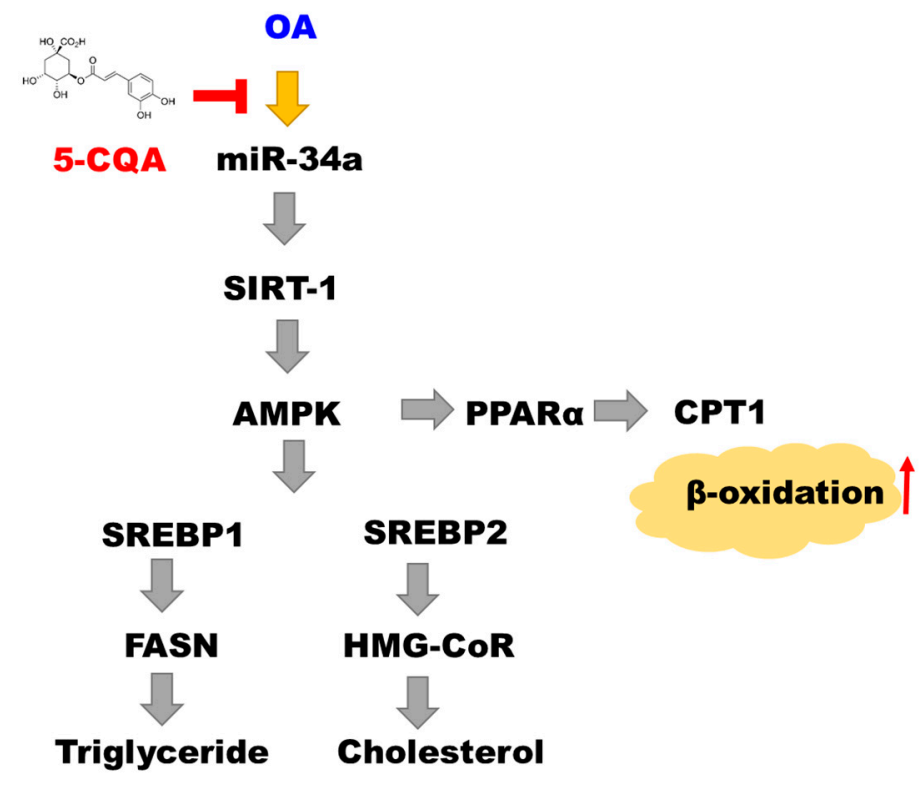

\section{Lipogenesis}

Figure 8. The mechanism by which 5-CQA alleviates lipid accumulation.

\section{Materials and Methods}

\subsection{Chemicals and Reagents}

Dulbecco's modified Eagle's medium (DMEM), fetal bovine serum (FBS), penicillinstreptomycin mixed antibiotics, L-glutamine, Dulbecco's phosphate-buffered saline (PBS), and Trypsin-EDTA were provided by Gibco/BRL (Gaithersburg, MD, USA). Monoclonal antibodies against AMPK (sc-74461), CPTI (sc-20669), SREBP1, SREBP2, HMG-CoA reductase (HMGCR; sc-271595), and PPAR $\alpha$ (sc-9000) were obtained from Santa Cruz (Santa Cruz, CA, USA). Cell Signaling Technology Inc (Beverly, MA, USA) provided antibodies against phosphor-AMPK (\#2535) and FASN (\#3180). The enhanced chemiluminescence kit was purchased from Amersham Life Sciences (Amersham, UK). Polyclonal antibodies against actin, $\mathrm{OA}$, and 5-CQA and other chemical reagents were procured from Sigma Chemical (St. Louis, MO, USA).

\subsection{Cell Culture}

The HepG2 cell line was purchased from the American Type Culture Collection (ATCC, Manassas, VA, USA), and the cells were resuspended in DMEM supplemented with $10 \%$ FBS (Gibco BRL Co., Gaithersburg, MD, USA), 1\% antibiotics (100 $\mathrm{gg} / \mathrm{mL}$ streptomycin and $100 \mathrm{U} / \mathrm{mL}$ penicillin) (Gibco BRL Co., Gaithersburg, MD, USA), 1\% sodium pyruvate (Hyclone, GE Healthcare, Pittsburge, PA, USA), and $2 \mathrm{mM}$ glutamine (Gibco BRL Co., Gaithersburg, MD, USA) at $37{ }^{\circ} \mathrm{C}$ in a humidified atmosphere with $5 \% \mathrm{CO}_{2}$.

\subsection{MTT Assay}

The cells $\left(5 \times 10^{4}\right)$ were plated in 24-well plates and then incubated with OA $(300 \mu \mathrm{M})$ bound to BSA or with BSA $(1 \mu \mathrm{L} / \mathrm{mL})$ alone as the control, or the cells were co-treated 
with OA and 5-CQA for 24-48 h. To measure cell viability, 3-(4,5-dimethylthizaol-2yl)-2,5- diphenyltetrazolium bromide (MTT; $0.2 \mathrm{mg} / \mathrm{mL}$ ) was added to each well, and incubation continued for $4 \mathrm{~h}$ at $37^{\circ} \mathrm{C}$. Thereafter, the culture medium was removed, and the cells were solubilized in DMSO to dissolve the formazan crystals formed. Optical density was measured using a spectrophotometer absorption at $563 \mathrm{~nm}$, and cell viability was calculated.

\subsection{Oil Red O Staining}

HepG2 cells $\left(5 \times 10^{5}\right.$ cells $\left./ \mathrm{mL}\right)$ were co-treated with 5-CQA and OA for $24 \mathrm{~h}$. The cells were fixed with paraformaldehyde (4\%) and stained with Oil Red O solution for $10 \mathrm{~min}$ at room temperature. After washing thrice, the cells were observed under a light microscope, and a red oil droplet was used in staining the cells to indicate OAinduced lipid accumulation. Finally, to quantify intracellular lipid stained with Oil Red O, isopropanol was added to each sample, and the absorbance was read using a microplate reader absorbance at $500 \mathrm{~nm}$.

\subsection{Nile Red Flow Cytometry Analysis}

To measure cellular neutral lipid droplet accumulation, HepG2 cells were stained using the Nile red method [50]. HepG2 cells were incubated with OA $(300 \mu \mathrm{M})$ bound to BSA or with BSA $(1 \mu \mathrm{L} / \mathrm{mL})$ alone as the control or were co-treated with OA and 5-CQA for $24 \mathrm{~h}$. After treatment, the cells were harvested with trypsin EDTA, washed three times with ice-cold PBS, and reacted with $1 \mu \mathrm{g} / \mathrm{mL}$ Nile red (Sigma-Aldrich, St. Louis, MO, USA) for $30 \mathrm{~min}$ at room temperature. Next, the cells were washed with PBS to remove unbound dye, and they were viewed using flow cytometry (Becton Dickinson Bioscience, San Jose, CA, USA). The cellular lipid content (a minimum of 10,000 cells per sample) was measured using BD biosciences FACscan with CellQuest ${ }^{\mathrm{TM}}$ Pro software (Becton Dickinson Bioscience, San Jose, CA, USA).

\section{6. miRNA Extraction and Real-Time PCR}

The total RNA of cells was extracted using the NucleoZOL reagent (Macherey-Nagel, Duren, Germany) according to the manufacturer's instructions. To quantify the expression of miR-34a, the TaqMan Small RNA Assay kit (Applied Biosystems, Carlsbad, CA, USA) was used to translate RNA to cDNA. According to the manufacturer's protocol, the Light Cycler Fast Start SYBR Green I Master Mix (Roche Diagnostics, Mannheim, Germany) was used to determine the purity and quantity of miR-34a. The primer sequences used to amplify miR-34a are as following (forward primer: $5^{\prime}$-UGGCAGUGUCUUAGCUGGUUGU-3'; reverse primer: $5^{\prime}$-GUGCAGGGUCCAGGU-3'). In each sample, RNU6B was used as an endogenous (internal) control. After amplification, the expression level of miR-34a was analyzed using Light Cycler software.

\subsection{Transfection with miR-34a Mimic and Inhibitor}

The cells were transfected using a Custom RNA system, the TOOLS Water DNA and RNA extraction kit (Biotools Co., Ltd., New Taipei, Taiwan), according to the manufacturer's instructions. In brief, 20 pmol miR-34a mimic (5'-UGGCAGUGUCUUAGCUGG UUGU-3') or miR-34a inhibitor (5'-ACAACCAGCUAAGACACUGCCA-3') was added to serum-free media and then mixed with $3 \mu \mathrm{L}$ of T-Pro Non-liposome transfection Reagent II per well for $15 \mathrm{~min}$ at room temperature [51,52]. The mixture was added to each culture dish, and the cells were cultured for $24 \mathrm{~h}$ at $37^{\circ} \mathrm{C}$ in a humidified atmosphere of $95 \%$ air with $5 \% \mathrm{CO}_{2}$.

\subsection{Western Blot Analysis}

After treatment, the medium was removed, and the cells were rinsed with PBS at room temperature. Next, $0.5 \mathrm{~mL}$ of cold radio-immunoprecipitation assay (RIPA) buffer $(10 \mu \mathrm{L} / \mathrm{mL}$ NP-40, $50 \mathrm{mM}$ Tris base, $1 \mu \mathrm{L} / \mathrm{mL}$ SDS, $5 \mu \mathrm{L} / \mathrm{mL}$ deoxycholic acid, 
$150 \mathrm{mM} \mathrm{NaCl}$, pH 7.5) with fresh protease inhibitor was added. The cells were scraped, and the lysate was centrifuged at $10,000 \times g$ for $10 \mathrm{~min}$. The cell lysate ( $50 \mu \mathrm{g}$ protein/sample) was mixed with an equal volume of RIPA buffer and then boiled for $10 \mathrm{~min}$, followed by analysis using sodium dodecyl sulfate polyacrylamide gel electrophoresis (SDS-PAGE). The protein was transferred from the gel to the nitrocellulose membrane (Millipore, Bedford, MA, USA) by using an electro-blotting apparatus. The membrane was further incubated with the indicated primary antibody, followed by incubation with a secondary antibody conjugated with horseradish peroxidase. The proteins were then visualized with Enhanced chemiluminescence (ECL) blotting detection reagents (Amersham Biosciences, Mountain View, CA, USA), and densitometric analysis was performed using the Fuji LAS-3000 imaging system (FUJFILM, Tokyo, Japan).

\subsection{Statistical Analysis}

All statistical analyses were performed using GraphPad Prism 7.0 (GraphPad Software, San Diego, CA, USA), and descriptive statistics are presented as mean \pm standard deviation of three independent experiments. Between-group differences were analyzed using the Student $t$-test. Moreover, $p<0.05$ was considered statistically significant.

Author Contributions: M.-H.Y., T.-H.T. and C.-J.W. wrote or contributed to the writing of the manuscript. T.-H.T. and C.-J.W. participated in research design. T.-W.H., T.-W.H., C.-Y.Y. and M.-H.Y. conducted experiments and performed data analysis. C.-C.W., S.-W.W. and T.-W.Y. contributed new reagents or analytic tools. All authors have read and agreed to the published version of the manuscript.

Funding: This work was supported by the Ministry of Science and Technology Grant (MOST 108-2320B-040-016-MY3 and MOST 102-2313-B-040-003-MY3), Taiwan. Digital Image Analyzer was performed in the Instrument Center of Chung Shan Medical University, which was supported by the Ministry of Science and Technology, Ministry of Education and Chung Shan Medical University, Taiwan.

Institutional Review Board Statement: Not applicable.

Informed Consent Statement: Not applicable.

Data Availability Statement: Not applicable.

Conflicts of Interest: The authors declare no conflict of interest.

\section{References}

1. Gaggini, M.; Morelli, M.; Buzzigoli, E.; DeFronzo, R.A.; Bugianesi, E.; Gastaldelli, A. Non-alcoholic fatty liver disease (NAFLD) and its connection with insulin resistance, dyslipidemia, atherosclerosis and coronary heart disease. Nutrients 2013, 5, 1544-1560. [CrossRef]

2. Neuschwander-Tetri, B.A. Non-alcoholic fatty liver disease. BMC Med. 2017, 15, 45. [CrossRef]

3. Serviddio, G.; Bellanti, F.; Vendemiale, G. Free radical biology for medicine: Learning from nonalcoholic fatty liver disease. Free Radic. Biol. Med. 2013, 65, 952-968. [CrossRef]

4. Horton, J.D.; Shimomura, I.; Brown, M.S.; Hammer, R.E.; Goldstein, J.L.; Shimano, H. Activation of cholesterol synthesis in preference to fatty acid synthesis in liver and adipose tissue of transgenic mice overproducing sterol regulatory element-binding protein-2. J. Clin. Investig. 1998, 101, 2331-2339. [CrossRef]

5. Horton, J.D.; Shah, N.A.; Warrington, J.A.; Anderson, N.N.; Park, S.W.; Brown, M.S.; Goldstein, J.L. Combined analysis of oligonucleotide microarray data from transgenic and knockout mice identifies direct SREBP target genes. Proc. Natl. Acad. Sci. USA 2003, 100, 12027-12032. [CrossRef] [PubMed]

6. Wong, T.Y.; Lin, S.-m.; Leung, L.K. The flavone luteolin suppresses SREBP-2 expression and post-translational activation in hepatic cells. PLoS ONE 2015, 10, e0135637. [CrossRef]

7. Liu, S.; Gao, Y.; Zhang, L.; Yin, Y.; Zhang, W. Rspo1/Rspo3-LGR4 signaling inhibits hepatic cholesterol synthesis through the AMPK $\alpha$-SREBP2 pathway. FASEB J. 2020, 34, 14946-14959. [CrossRef]

8. Price, N.L.; Gomes, A.P.; Ling, A.J.; Duarte, F.V.; Martin-Montalvo, A.; North, B.J.; Agarwal, B.; Ye, L.; Ramadori, G.; Teodoro, J.S. SIRT1 is required for AMPK activation and the beneficial effects of resveratrol on mitochondrial function. Cell Metab. 2012, 15, 675-690. [CrossRef]

9. Wang, Q.; Liu, S.; Zhai, A.; Zhang, B.; Tian, G. AMPK-mediated regulation of lipid metabolism by phosphorylation. Biol. Pharm. Bull. 2018, 41, 985-993. [CrossRef] 
10. Chyau, C.-C.; Wang, H.-F.; Zhang, W.-J.; Chen, C.-C.; Huang, S.-H.; Chang, C.-C.; Peng, R.Y. Antrodan alleviates high-fat and high-fructose diet-induced fatty liver disease in C57BL/ 6 mice model via AMPK/Sirt1/SREBP-1c/PPAR $\gamma$ pathway. Int. J. Mol. Sci. 2020, 21, 360. [CrossRef]

11. Huang, Y.; Yan, Y.; Xv, W.; Qian, G.; Li, C.; Zou, H.; Li, Y. A new insight into the roles of MiRNAs in metabolic syndrome. BioMed Res. Int. 2018, 2018, 7372636. [CrossRef]

12. Das, S.; Mohamed, I.N.; Teoh, S.L.; Thevaraj, T.; Ku Ahmad Nasir, K.N.; Zawawi, A.; Salim, H.H.; Zhou, D.K. Micro-RNA and the features of metabolic syndrome: A narrative review. Mini Rev. Med. Chem. 2020, 20, 626-635. [CrossRef] [PubMed]

13. Biersack, B. Current state of phenolic and terpenoidal dietary factors and natural products as non-coding RNA/microRNA modulators for improved cancer therapy and prevention. Non-Coding RNA Res. 2016, 1, 12-34. [CrossRef]

14. Zobeiri, M.; Parvizi, F.; Kalhori, M.R.; Majnooni, M.B.; Farzaei, M.H.; Abdollahi, M. Targeting miRNA by Natural Products: A Novel Therapeutic Approach for Nonalcoholic Fatty Liver. Evid.-Based Complementary Altern. Med. 2021, 2021, 6641031. [CrossRef]

15. Torres, L.; Cogliati, B.; Otton, R. Green tea prevents NAFLD by modulation of miR-34a and miR-194 expression in a high-fat diet mouse model. Oxidative Med. Cell. Longev. 2019, 2019, 4168380. [CrossRef]

16. Xu, Y.; Zhu, Y.; Hu, S.; Pan, X.; Bawa, F.C.; Wang, H.H.; Wang, D.Q.-H.; Yin, L.; Zhang, Y. Hepatocyte miR-34a is a key regulator in the development and progression of non-alcoholic fatty liver disease. Mol. Metab. 2021, 51, 101244. [CrossRef] [PubMed]

17. Lee, Y.-J.; Hsu, J.-D.; Lin, W.-L.; Kao, S.-H.; Wang, C.-J. Upregulation of caveolin-1 by mulberry leaf extract and its major components, chlorogenic acid derivatives, attenuates alcoholic steatohepatitis via inhibition of oxidative stress. Food Funct. 2017, 8, 397-405. [CrossRef]

18. Peng, C.-H.; Lin, H.-T.; Chung, D.-J.; Huang, C.-N.; Wang, C.-J. Mulberry Leaf Extracts prevent obesity-induced NAFLD with regulating adipocytokines, inflammation and oxidative stress. J. Food Drug Anal. 2018, 26, 778-787. [CrossRef]

19. Ann, J.-Y.; Eo, H.; Lim, Y. Mulberry leaves (Morus alba L.) ameliorate obesity-induced hepatic lipogenesis, fibrosis, and oxidative stress in high-fat diet-fed mice. Genes Nutr. 2015, 10,1-13. [CrossRef]

20. Lee, M.R.; Kim, J.E.; Park, J.W.; Kang, M.J.; Choi, H.J.; Bae, S.J.; Choi, Y.W.; Kim, K.M.; Hong, J.T.; Hwang, D.Y. Fermented mulberry (Morus alba) leaves suppress high fat diet-induced hepatic steatosis through amelioration of the inflammatory response and autophagy pathway. BMC Complementary Med. Ther. 2020, 20, 283. [CrossRef]

21. Bajko, E.; Kalinowska, M.; Borowski, P.; Siergiejczyk, L.; Lewandowski, W. 5-O-Caffeoylquinic acid: A spectroscopic study and biological screening for antimicrobial activity. LWT-Food Sci. Technol. 2016, 65, 471-479. [CrossRef]

22. Hao, S.; Xiao, Y.; Lin, Y.; Mo, Z.; Chen, Y.; Peng, X.; Xiang, C.; Li, Y.; Li, W. Chlorogenic acid-enriched extract from Eucommia ulmoides leaves inhibits hepatic lipid accumulation through regulation of cholesterol metabolism in HepG2 cells. Pharm. Biol. 2016, 54, 251-259. [CrossRef]

23. Tsai, K.L.; Hung, C.H.; Chan, S.H.; Hsieh, P.L.; Ou, H.C.; Cheng, Y.H.; Chu, P.M. Chlorogenic acid protects against oxLDL-induced oxidative damage and mitochondrial dysfunction by modulating SIRT1 in endothelial cells. Mol. Nutr. Food Res. 2018, 62, 1700928. [CrossRef]

24. Randy, A.; Kim, M.; Nho, C.W. Ligularia fischeri and its constituent 3, 4-dicaffeoylquinic acid improve obesity-induced nonalcoholic fatty liver disease by regulating lipid metabolism and activating AMPK. J. Funct. Foods 2016, 27, 1-16. [CrossRef]

25. Huang, K.; Liang, X.c.; Zhong, Y.1.; He, W.y.; Wang, Z. 5-Caffeoylquinic acid decreases diet-induced obesity in rats by modulating PPAR $\alpha$ and LXR $\alpha$ transcription. J. Sci. Food Agric. 2015, 95, 1903-1910. [CrossRef]

26. Kim, D.; Touros, A.; Kim, W.R. Nonalcoholic fatty liver disease and metabolic syndrome. Clin. Liver Dis. 2018, 22, 133-140. [CrossRef]

27. Shi, L.; Karrar, E.; Wang, X. Sesamol ameliorates hepatic lipid accumulation and oxidative stress in steatosis HepG2 cells via the PPAR signaling pathway. J. Food Biochem. 2021, 45, e13976. [CrossRef]

28. Tian, Y.; Ma, J.; Wang, W.; Zhang, L.; Xu, J.; Wang, K.; Li, D. Resveratrol supplement inhibited the NF-kB inflammation pathway through activating AMPK $\alpha$-SIRT1 pathway in mice with fatty liver. Mol. Cell. Biochem. 2016, 422, 75-84. [CrossRef] [PubMed]

29. Bougarne, N.; Weyers, B.; Desmet, S.J.; Deckers, J.; Ray, D.W.; Staels, B.; De Bosscher, K. Molecular actions of PPAR $\alpha$ in lipid metabolism and inflammation. Endocr. Rev. 2018, 39, 760-802. [CrossRef] [PubMed]

30. Wang, L.; Sun, M.; Cao, Y.; Ma, L.; Shen, Y.; Velikanova, A.A.; Li, X.; Sun, C.; Zhao, Y. miR-34a regulates lipid metabolism by targeting SIRT1 in non-alcoholic fatty liver disease with iron overload. Arch. Biochem. Biophys. 2020, 695, 108642. [CrossRef]

31. Parlati, L.; Régnier, M.; Guillou, H.; Postic, C. New targets for NAFLD. JHEP Rep. 2021, 3, 100346. [CrossRef]

32. Leoni, S.; Tovoli, F.; Napoli, L.; Serio, I.; Ferri, S.; Bolondi, L. Current guidelines for the management of non-alcoholic fatty liver disease: A systematic review with comparative analysis. World J. Gastroenterol. 2018, 24, 3361. [CrossRef]

33. Yadav, A.; Shah, N.; Tiwari, P.K.; Javed, K.; Cheng, Q.; Aidhen, I.S.; Bröer, S. Novel chemical scaffolds to inhibit the neutral amino acid transporter B0AT1 (SLC6A19), a potential target to treat metabolic diseases. Front. Pharmacol. 2020, 11, 140. [CrossRef]

34. Rafiei, H.; Omidian, K.; Bandy, B. Dietary polyphenols protect against oleic acid-induced steatosis in an in vitro model of NAFLD by modulating lipid metabolism and improving mitochondrial function. Nutrients 2019, 11, 541. [CrossRef]

35. Sui, G.-G.; Xiao, H.-B.; Lu, X.-Y.; Sun, Z.-L. Naringin activates AMPK resulting in altered expression of SREBPs, PCSK9, and LDLR to reduce body weight in obese C57BL/6J mice. J. Agric. Food Chem. 2018, 66, 8983-8990. [CrossRef]

36. Blade, C.; Baselga-Escudero, L.; Arola-Arnal, A. microRNAs as new targets of dietary polyphenols. Curr. Pharm. Biotechnol. 2014, 15, 343-351. [CrossRef] [PubMed] 
37. Tajner-Czopek, A.; Gertchen, M.; Rytel, E.; Kita, A.; Kucharska, A.Z.; Sokół-Łętowska, A. Study of Antioxidant Activity of Some Medicinal Plants Having High Content of Caffeic Acid Derivatives. Antioxidants 2020, 9, 412. [CrossRef]

38. Wang, S.; Sarriá, B.; Mateos, R.; Goya, L.; Bravo-Clemente, L. TNF- $\alpha$-induced oxidative stress and endothelial dysfunction in EA. hy926 cells is prevented by mate and green coffee extracts, 5 -caffeoylquinic acid and its microbial metabolite, dihydrocaffeic acid. Int. J. Food Sci. Nutr. 2019, 70, 267-284. [CrossRef] [PubMed]

39. Santana-Gálvez, J.; Cisneros-Zevallos, L.; Jacobo-Velázquez, D.A. Chlorogenic acid: Recent advances on its dual role as a food additive and a nutraceutical against metabolic syndrome. Molecules 2017, 22, 358. [CrossRef] [PubMed]

40. Lee, J.; Padhye, A.; Sharma, A.; Song, G.; Miao, J.; Mo, Y.-Y.; Wang, L.; Kemper, J.K. A pathway involving farnesoid X receptor and small heterodimer partner positively regulates hepatic sirtuin 1 levels via microRNA-34a inhibition. J. Biol. Chem. 2010, 285, 12604-12611. [CrossRef]

41. Flowers, E.; Froelicher, E.S.; Aouizerat, B.E. MicroRNA regulation of lipid metabolism. Metabolism 2013, 62, 12-20. [CrossRef]

42. Salvoza, N.C.; Klinzing, D.C.; Gopez-Cervantes, J.; Baclig, M.O. Association of circulating serum miR-34a and miR-122 with dyslipidemia among patients with non-alcoholic fatty liver disease. PLoS ONE 2016, 11, e0153497. [CrossRef] [PubMed]

43. Majeed, Y.; Halabi, N.; Madani, A.Y.; Engelke, R.; Bhagwat, A.M.; Abdesselem, H.; Agha, M.V.; Vakayil, M.; Courjaret, R.; Goswami, N. SIRT1 promotes lipid metabolism and mitochondrial biogenesis in adipocytes and coordinates adipogenesis by targeting key enzymatic pathways. Sci. Rep. 2021, 11, 8177. [CrossRef]

44. Li, X.; Lian, F.; Liu, C.; Hu, K.-Q.; Wang, X.-D. Isocaloric pair-fed high-carbohydrate diet induced more hepatic steatosis and inflammation than high-fat diet mediated by miR-34a/SIRT1 axis in mice. Sci. Rep. 2015, 5, 16774. [CrossRef] [PubMed]

45. Hou, X.; Xu, S.; Maitland-Toolan, K.A.; Sato, K.; Jiang, B.; Ido, Y.; Lan, F.; Walsh, K.; Wierzbicki, M.; Verbeuren, T.J. SIRT1 regulates hepatocyte lipid metabolism through activating AMP-activated protein kinase. J. Biol. Chem. 2008, 283, 20015-20026. [CrossRef]

46. Meng, S.; Cao, J.; Feng, Q.; Peng, J.; Hu, Y. Roles of chlorogenic acid on regulating glucose and lipids metabolism: A review. Evid.-Based Complementary Altern. Med. 2013, 2013, 801457. [CrossRef] [PubMed]

47. Yan, J.; Wang, M.; Lü, J. Determination of rutin, quercetin, and chlorogenic acid in mulberry leaves by capillary zone electrophoresis. Anal. Lett. 2004, 37, 3287-3297. [CrossRef]

48. Zhai, K.-F.; Duan, H.; Shi, S.-X.; Liu, L.-L.; Cao, W.-G.; Gao, G.-Z.; Shan, L.-L. Synchronised determination of chlorogenic acid and five flavonoids in mulberry leaves using HPLC with photodiode array detection. Qual. Assur. Saf. Crop. Foods 2018, 10, 175-182. [CrossRef]

49. Liang, N.; Dupuis, J.H.; Yada, R.Y.; Kitts, D.D. Chlorogenic acid isomers directly interact with Keap 1-Nrf2 signaling in Caco-2 cells. Mol. Cell. Biochem. 2019, 457, 105-118. [CrossRef] [PubMed]

50. Greenspan, P.; Mayer, E.P.; Fowler, S.D. Nile red: A selective fluorescent stain for intracellular lipid droplets. J. Cell Biol. 1985, 100, 965-973. [CrossRef] [PubMed]

51. Hart, M.; Rheinheimer, S.; Leidinger, P.; Backes, C.; Menegatti, J.; Fehlmann, T.; Grässer, F.; Keller, A.; Meese, E. Identification of miR-34a-target interactions by a combined network based and experimental approach. Oncotarget 2016, 7, 34288. [CrossRef] [PubMed]

52. Xue, F.; Yang, J.; Li, Q.; Zhou, H. Down-regulation of microRNA-34a-5p promotes trophoblast cell migration and invasion via targetting Smad4. Biosci. Rep. 2019, 39, BSR20181631. [CrossRef] [PubMed] 